\title{
Stage IV Skin Cancer
}

National Cancer Institute

\section{Source}

National Cancer Institute. Stage IV Skin Cancer. NCI Thesaurus. Code C5584.

Stage IV includes: (T1, N2, M0); (T2, N2, M0); (T3, N2, M0); (T Any, N3, M0); (T4, N Any, M0); (T Any, N Any, M1). T1: Tumor $2 \mathrm{~cm}$ or less in greatest dimension with less than two high-risk features. T2: T umor size greater than $2 \mathrm{~cm}$ in greatest dimension or tumor of any size with two or more high-risk features. T3: T umor with invasion of maxilla, mandible, orbit, or temporal bone. T4: Tumor with invasion of skeleton or perineural invasion of skull base. N0: No regional lymph node metastasis. N2: Metastasis in a single ipsilateral lymph node, more than $3 \mathrm{~cm}$ but not more than $6 \mathrm{~cm}$ in greatest dimension; or in multiple ipsilateral lymph nodes, none more than $6 \mathrm{~cm}$ in greatest dimension; or in bilateral or contralateral lymph nodes, none more than $6 \mathrm{~cm}$ in greatest dimension. N3: Metastasis in a lymph node, more than $6 \mathrm{~cm}$ in greatest dimension. M1: Distant metastases. (AJCC 7th Ed.) 